\title{
вмJ Global Health Thinking beyond implementation: context and culture in global mental health
}

\author{
Cristian R Montenegro (D) ,1,2 Francisco Ortega ${ }^{3}$
}

To cite: Montenegro CR, Ortega F. Thinking beyond implementation: context and culture in global mental health. BMJ Global Health 2020;5:e004539. doi:10.1136/ bmjgh-2020-004539

Received 23 November 2020 Revised 4 December 2020 Accepted 7 December 2020

Check for updates

(C) Author(s) (or their employer(s)) 2020. Re-use permitted under CC BY-NC. No commercial re-use. See rights and permissions. Published by BMJ.

${ }^{1}$ Nursing School, Pontificia Universidad Católica de Chile, Santiago, Chile

${ }^{2}$ Millennium Institute for Depression and Personality Research (MIDAP), Santiago, Chile

${ }^{3}$ Institute for Social Medicine, State University of Rio de Janeiro, Rio de Janeiro, Brazil

Correspondence to Dr Cristian R Montenegro; cmontenegrocortes@gmail.com

\section{INTRODUCTION}

Global mental health is a field of research and intervention that aims to improve access to mental health on a global scale. ${ }^{1}$ A basic tenet in the field is the existence of a large 'treatment gap' for most mental disorders, especially in low-income and middle-income countries, and the need to 'scale up' interventions through, among other things, 'task shifting/sharing' to/with community health workers, traditional healers and peers. ${ }^{2}$ The rise of global mental health has unearthed old controversies in psychiatry such as the universality vs cultural specificity of mental disorders, their expressions and their relationship with forces beyond the individual. ${ }^{34}$

The consolidation of global mental health as a field has been accompanied by a strong call for interventions to be contextualised and adapted to cultural and social realities. Context here refers to, among other things, formal and informal health and social care systems, cultural values and norms, and social and political processes. ${ }^{56} \mathrm{~A}$ central argument in this call is that mental health is, maybe to a higher degree than physical health, rooted in local definitions of personhood and the good life and that these definitions are historically and socially situated. Mental health interventions need to make sense both for local practitioners and for service users and, therefore, attention to context is crucial.

Usually, these calls are addressed at a relatively specific type of intervention, involving services that start-or are designed-in one place to be then implemented in another, and whose success depends on local uptake by providers and service users. In its most simple form, this type of intervention involves a logic with three broad steps: (1) an intervention, initially conceived in the global north; (2) a set of implementers, usually trained, supervised and/or supported by representatives of global initiatives and (3) local populations, with their current and potential needs (see figure 1). In this logic of implementation, culture and context constitute layers that interventions penetrate with more or less success, acting as obstacles or enhancers for mental health and well-being.

In this editorial, we draw on examples from Brazil and Chile to explore how, within local mental health systems, 'contexts' behave in ways that do not necessarily follow the logic of implementation. Context and culture are not only facilitators or barriers; they are contentious dimensions of identity (as in the case of Brazil), and their relevance is weakened by global assessment technologies (as in the case of Chile). We aim to unsettle and expand the relatively circumscribed place given to culture and context in global mental health. Brazil and Chile are two countries that stand in an ambiguous position concerning the implicit priorities of global mental health ${ }^{7}$; countries that, while not easily classifiable as producers or receivers of global mental health interventions, dynamically respond to its normative and epistemic coordinates. A secondary aim for this editorial is, therefore, to explore the nature of this interaction.

\section{BRAZIL: THE LOCAL (IN)ACCESSIBILITY OF CONTEXT AND CULTURE}

The implementation logic of global mental health assumes context and culture are in different degrees accessible to interventions. The case of Brazil evinces that cultural determinants are actively neglected in the mental health field by local practitioners and policymakers. Cultural differences do not constitute a relevant level of engagement with service users. The imaginary of ethnic uniformity is a barrier to the implementing of culturally sensitive interventions.

One of the divergences between Global Mental Health and public mental healthcare 


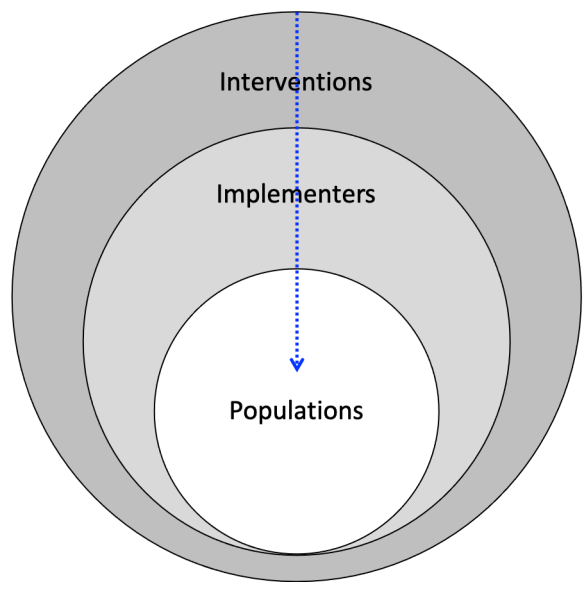

Figure 1 This diagram shows three broad steps it the life of global mental health projects and a trajectory of action that goes from intervention to population.

in Brazil regards the role of cultural differences within mental health policies. While the former attributes (in one way or another) high relevance to the cultural aspects of mental healthcare, these are concealed within mental health services in the country-a process that we called 'silencing of culture'. ${ }^{4}$ This erasure and internal contestation of culture are related to the imaginary national understanding of Brazil. According to this understanding, 'cultural uniformity', as Brazilian anthropologist Ribeiro ${ }^{8}$ writes, is the most important consequence of the formation process of the Brazilian people as an ethnically homogeneous nation, a national ethnicity, integrating cultural, racial, ethnic and regional differences. Despite the national narrative of cultural uniformity, Ribeiro and others consider the Brazilian society as profoundly stratified. However, the stratification that receives policy attention are not those of culture and ethnicity, but those of class.

This cultural understanding has influenced the Brazilian Psychiatric Reform as well as mental health policies and service organisation in the country, which have privileged class stratification and socioeconomic inequality at the expense of cultural diversity. Ongoing criticism of this emphasis, advanced by indigenous, black and lesbian, gay, bisexual and transgender (LGBT) movements has so far not significatively impacted the theoretical and practical foundations of Brazilian mental healthcare. The Brazilian healthcare reform of the 1980s - that culminated in the creation of the Unified Health System (SUS) in 1990-focused on decentralisation and the recognition of healthcare as a universal social right. Like psychiatric reform, it did not sufficiently emphasise health issues associated with ethnic, racial or cultural diversity. Therefore, even though there are particular healthcare policies for specific vulnerable populations in the country (black, indigenous and LGBT populations), they have a marginal place, without a strong legal basis and financing support. This frequently contributes to worse health outcomes. ${ }^{9} 10$
Against this background, the significance of 'cultural differences' for causes, courses, and outcomes as well as cultural explanations for mental distress were neither incorporated into mental health policies nor into the practice of most professionals in the country. The erasure of culture results in ignorance or misrecognition of the cultural dimension of mental distress within mental health practices and services, leading in some cases to its rejection, reification or caricature. ${ }^{411}$ Therefore, a meaningful global mental health intervention in countries like Brazil cannot merely assume context and culture as something directly accessible. Cultural determinants are being actively-although not consciously or deliberatelyhidden at the local level. A careful examination of local and historical configurations, which in this case involve the process and pattern of national identity formation, is necessary before developing meaningful interventions for practitioners and service users.

\section{CHILE: GLOBAL ASSESSMENT FRAMEWORKS AND EPISTEMIC ALIENATION}

While focusing on interventions, implementers and local populations, the rationality of implementation simplified in figure 1 does not consider a critical form of global influence-that is, the role of global metrics and standardisations and their actual and potential effects at the local level. We will use the case of Chile to exemplify this tendency.

Global frameworks and standards play a crucial role in Latin America's mental health policy. The Caracas Declaration (1990), championed by the Pan American Health Organization (PAHO), signed by mental health leaders across the continent, called for downsizing psychiatric hospitals, the development of community-based alternatives and the integration of mental health into primary care. The declaration coincided with Chile's return to democracy, becoming the model for mental health planning to this day. ${ }^{12}$ And, while progress has been uneven across countries, the declaration created a lasting framework for policy design and evaluation in the region, with $\mathrm{PAHO}$ as its leading promoter.

In line with PAHO's and WHO's standards, in 2005 and 2014, Chile implemented the Assessment Instrument for Mental Health Systems or WHO Assessment Instrument for Mental Health Systems (AIMS). ${ }^{13}$ Chile also reports its mental health situation-defined by WHO's indicators-for the Mental Health Atlas; it did in 2001, 2005, 2014 and, most recently, in 2020. Other WHO initiatives, such as the QualityRights tool, were incorporated in 2015, together with policy assessment tools based on comparison requirements of the Organisation for Economic Co-operation and Development (OECD) and the Asia-Pacific Economic Cooperation .

This growing set of information demands only partially overlaps with local information needs, producing a disjuncture between global and local data gathering and reporting routines. The production of information 
to respond to these demands, in contexts of precarity and with historically weak mental health systems, shifts resources away from the local definition and identification of problems, whose consideration is key to improve services. ${ }^{14}$ As Adams and colleagues reflect, such investment in global scale mandates and interventions-including assessment interventions-generate an 'unwillingness (or inability) to accommodate and adjust to specific local circumstances that might actually improve outcomes'. ${ }^{15}$

Furthermore, the fact that these information demands are promoted as mechanisms of self-assessment turns this disjuncture into a form of epistemic alienation, 'the distortion of one's native way of thinking, and of seeing and speaking of one's own reality'. ${ }^{16}$ Through these tools, what a country knows about itself is based on variables designed for comparison. Potentially comparable aspects assumed to be present in a larger group of countries, gain prominence and shape the value and relevance of local information, excluding aspects of reality that could form the basis for the identification of needs and the creation of solutions.

\section{CONCLUSIONS}

The implementation of any given intervention can either succeed or fail depending on its local uptake. Nonetheless, while context and culture need to be adequately understood in order to address the mental health needs of a population, they are simultaneously subjected to local negotiation related to history, identity and epistemic practices.

Brazil and Chile demonstrate the local complexity of context and culture beyond the requirements of implementing global initiatives. The example of Brazil reveals that the historical-although contested-creation of a national 'identity' that privileges homogeneity, obscures the expression of diversity in the design of mental health policy. A focus on class and inequality as central markers of difference-and as the main horizon for healthcare reform-minimises the relevance of cultural diversity in the definition of mental health policy and in the actions of practitioners. In the case of Chile, local contexts and cultural specificity are rendered irrelevant by the selectivity introduced by global, comparative self-assessment frameworks. The very idea of 'adaptation' loses its meaning, as what is known about the mental health system-its efficacy and reach-is already based on globally defined indicators, creating an epistemic circularity.

In summary, this editorial highlights two processes that problematise an implementation-based notion of context and culture: the local silencing of culture and its impact on mental health policy in Brazil, and the epistemic alienation created by globally defined self-assessments tools in Chile. Rather than static layers in which intervention can be 'adapted', it is important for global (mental) health to recognise that culture and context are internally contested, and that their meaning and relevance are rooted in local history and identity. Critical concerns about exporting knowledge and practices need to be supplemented with a careful examination of the internal complexity of culture and context and how they are made visible and negotiated alongside global and local policy ambitions.

Twitter Cristian R Montenegro @Cris_Monteneg

Contributors CRM and F0 contributed equality to the writing of this editorial.

Funding The authors have not declared a specific grant for this research from any funding agency in the public, commercial or not-for-profit sectors.

Competing interests None declared.

Patient consent for publication Not required.

Provenance and peer review Commissioned; externally peer reviewed.

Data availability statement No datasets were generated or analyzed for the creation of this editorial.

Open access This is an open access article distributed in accordance with the Creative Commons Attribution Non Commercial (CC BY-NC 4.0) license, which permits others to distribute, remix, adapt, build upon this work non-commercially, and license their derivative works on different terms, provided the original work is properly cited, appropriate credit is given, any changes made indicated, and the use is non-commercial. See: http://creativecommons.org/licenses/by-nc/4.0/.

ORCID iD

Cristian R Montenegro http://orcid.org/0000-0001-9291-267X

\section{REFERENCES}

1 Patel V, Prince M. Global mental health: a new global health field comes of age. JAMA 2010;303:1976-7.

2 Lancet Global Mental Health Group, Chisholm D, Flisher AJ, et al. Scale up services for mental disorders: a call for action. Lancet 2007;370:1241-52.

3 Bemme D, Kirmayer LJ. Global mental health: interdisciplinary challenges for a field in motion. Transcult Psychiatry 2020;57:3-18.

4 Ortega F, Wenceslau LD. Challenges for implementing a global mental health agenda in Brazil: The "silencing" of culture. Transcult Psychiatry 2020;57:57-70.

5 Montenegro CR, Cornish F. 'It is not the State's fault that we have a person like this': relations, institutions and the meaning of 'rights' to carers of People with Psychosocial Disabilities in Chile. Glob Ment Health 2015;2:e22 http://journals.cambridge.org/article_ S2054425115000205

6 Read UM, Adiibokah E, Nyame S. Local suffering and the global discourse of mental health and human rights: an ethnographic study of responses to mental illness in rural Ghana. Global Health 2009;5:13.

7 Misra S, Stevenson A, Haroz EE, et al. 'Global mental health': systematic review of the term and its implicit priorities. BJPsych Open 2019;5:e47.

8 Ribeiro D. The Brazilian people: the formation and meaning of Brazil. Gainesville: University Press of Florida, 2000.

9 Boccolini CS, de Souza Junior PRB. Inequities in healthcare utilization: results of the Brazilian National health survey, 2013. Int J Equity Health 2016;15:150.

10 Popadiuk GS, Oliveira DC, Signorelli MC. The National policy for comprehensive health of lesbians, Gays, Bisexuals and transgender (LGBT) and access to the sex reassignment process in the Brazilian unified health system (SUS): progress and challenges. Cien Saude Colet 2017;22:1509-20.

11 Coutinho MFC, Portugal CM. Articulations between the global mental health project and the cultural aspects of care in the psychosocial care and primary health care Network in Brazil. Physis: Revista de Saúde Coletiva [Internet], 2020. Available: http://www.scielo.br/scielo.php?script=sci_abstract\&pid=S0103$73312020000200602 \&$ Ing=en\&nrm=iso\&tIng=en

12 et alMinoletti A, Sepúlveda R, Gómez M. Análisis de la gobernanza en la implementación del modelo comunitario de salud mental en Chile. Revista Panamericana de Salud Pública [Internet], 2018. Available: http://iris.paho.org/xmlui/handle/123456789/49515

13 WHO. World Health Organization assessment instrument for mental health systems-WHO-AIMS version 2.2 [Internet]. Geneva: World 
Health Organization, 2005. http://apps.who.int/iris/handle/10665/ 70771

14 Abimbola S. The foreign gaze: authorship in academic global health BMJ Glob Health 2019;4:e002068.

15 Adams V, Burke NJ, Whitmarsh I. Slow research: thoughts for a movement in global health. Med Anthropol 2014;33:179-97.
16 Mboa Nkoudou T, Paul Eve M, Gray J. Epistemic Alienation in African Scholarly Communications: Open Access as a Pharmakon. In: Reassembling scholarly communications histories, infrastructures, and global politics of open access. MIT Press, 2020. https://direct. mit.edu/books/book/4933/chapter/625153/Epistemic-Alienation-inAfrican-Scholarly 